\title{
Le Camion (1977) de Marguerite Duras: palabra y filme
}

\author{
Luciene Guimaraes de Oliveira
}

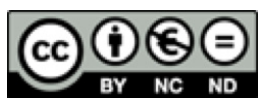

Esta obra está bajo una licencia Creative Commons

Reconocimiento-No comercial-Sin Obra Derivada 
Artículos

\title{
Le Camion (1977) de Marguerite Duras: palabra y filme ${ }^{1}$
}

\author{
Luciene Guimaraes de Oliveira \\ Universidad Laval, Canadá \\ guimalucienne@gmail.com
}

\begin{abstract}
Recibido: 28 de setiembre de 2016 Aprobado: 28 de octubre de 2016 Resumen
\end{abstract}

En la película Le Camión (El camión, 1997), de Marguerite Duras, en lugar de ver un filme, vemos a la guionista, Duras, y al actor Gérard Depardieu, leer un guion. A través de ese proceso inconcluso de eso que habría sido un film, Duras propone al espectador imaginar una historia antes que verla en imágenes. En ese acto de lectura intermedial, el espectador asiste a un filme que reposa casi exclusivamente en la palabra y en el que podemos constatar el cruce de elementos característicos del texto literario, de la imagen y de la escena. Este artículo propone explorar la paradoja que reside en este proyecto de obra inacabada, propio de la poética durasiana.

Palabras clave: Marguerite Duras; intermedialidad; cine, teatro; literatura

\begin{abstract}
In Marguerite Duras' movie Le Camion (The Truck, 1997), instead of watching a film, we can see Duras, the scriptwriter, and Gérard Depardieu, the actor, reading a script. Through that unfinished process of what could have been a film, Duras wants the spectator to imagine a story rather than watching it (in images). Through the act of intermediate reading, the spectator witnesses a talky film, where we can perceive

${ }^{1}$ Dentro de la obra de Marguerite Duras, el conjunto "Texto teatro filme" alude al subtítulo de los textos literario y fílmico India Song (1974). No quiere esto decir, sin embargo, que establezcamos una comparación directa entre estas dos creaciones. Por otra parte, este subtítulo hace también referencia, de manera implícita, al concepto de "entreescritura" (entrecriture), elaborado por Julie Beaulieu para examinar la intermedialidad en la obra durasiana, la cual se desarrollará en este artículo.
\end{abstract}


Artículos

the characteristic elements belonging to the literary text, the image and the scene. This article sets out an exploration to the paradox present on this project of an incomplete piece, typical in Duras' Poetics.

Keywords: Marguerite Duras; intermediality; cinema, drama; literature 
En la película Le Camion (El camión, 1977), la escritora, y cineasta, y el actor Gérard Depardieu leen el guion de lo que habría sido un filme, de haber sido rodado. La lectura de ese guion jamás ejecutado desestabiliza al espectador que está frente a la pantalla y desafía las convenciones representacionales del cine. En el presente artículo, se propone una reflexión alrededor de las prácticas intermediales que ligan el texto, el teatro y el filme y que subyacen en el libro y la película Le Camion.

Es pertinente situar esta obra de naturaleza híbrida dentro del conjunto de las creaciones de Marguerite Duras. Aunque puede decirse que la obra durasiana "incluye" novelas, textos teatrales, guiones y películas, lo cierto es que la escritura de Duras es subversiva y no se deja limitar por los géneros literarios o por las formas mediáticas. En el seno del texto durasiano encontramos frecuentemente el pasaje del teatro hacia la novela, o del teatro al poema; hasta ese punto, su escritura oscila entre los géneros y es fundamentalmente intermedial. Sobre esto, Madeleine Borgomano, una de las principales especialistas en la obra de Duras, ha denominado este desplazamiento del libro hacia la escena y la pantalla como una "escritura fílmica"2.

El cine se revela como indisociable de un proceso continuo de escritura. $\mathrm{Al}$ interior del mismo podemos destacar, según Borgomano, el parentesco estrecho entre teatro y cine: ellos "se sitúan los dos en el dominio de la mímesis: representación, escena o algo que se interpreta está en juego. Se sitúan igualmente en el dominio de la voz humana, lo que nos saca de la visión original del cine" (Borgomano, 1985, p. 29). En el caso de Le Camion, lo que parece estar en juego es precisamente el proyecto inacabado de un filme. Si bien el texto está "acabado", la película no ha sido nunca rodada.

Es evidente que en el cine, el guion precede la realización del filme pero, en lo que concierne a Le Camion, la puesta en escena de la lectura del guion, leído por Duras y Depardieu, deviene propiamente el filme que cuenta la historia de una mujer recogida en la carretera. Los personajes, la mujer y el chofer aparecen poco a poco, conforme la lectura avanza, pero no son nunca mostrados. La película, la que sí fue rodada y ahora vemos, alterna las escenas en exteriores de un camión que recorre un suburbio parisino y las secuencias en interiores, rodadas en una habitación de la casa de Duras. Es por el diálogo que allí se desarrolla que la mayor parte de la información nos es comunicada.

Con su puesta en escena de la lectura y del diálogo entre Duras y Depardieu, el filme inscribe la palabra en un discurso teatral, sin que por ello se imponga propiamente como texto

\footnotetext{
${ }^{2}$ Se trata precisamente del título del estudio de Borgomano, Lécriture filmique de Marguerite Duras, publicado en 1985 y que se puede considerar como el primero dedicado a la cinematografía de Duras.
} 
dramático. Aunque el texto que pasa por la voz nos recuerda una representación teatral, no se trata de una representación porque la espontaneidad de los "actores" (Duras y Depardieu) es contraria a cualquier actuación. Además, la voz en off empleada en las escenas en exteriores, evocando fuera de campo a Duras o Depardieu, reafirma la cinematograficidad del relato.

Es así como la escritura de Le Camion, que apareció como libro en 1977, oscila entre la del teatro y la del cine, y abordarla según la triada "texto teatro filme" implica dar realce a su carácter intermedial. En efecto, la denominación "texto teatro filme", según Michelle Royer, "vehicula varios sistemas semióticos: palabras, ruidos, imágenes, códigos gestuales, puesta en escena, escritura, y evoca las mutaciones posibles del texto a través de diversos medios" (1985, p. 23).

A la manera de India Song, cuyo subtítulo texto teatro filme da cuenta de su hibridez, el texto de Le Camion (que funciona como guion sin serlo enteramente) muestra también el ligamen entre lo literario, lo escénico y lo fílmico. Las indicaciones escénicas en ese texto dramático no son respetadas; por el contrario, estas son reemplazadas por otras marcas, como el tiempo o el silencio, pero de una manera distinta a la usual en el cine y el teatro. En general, la indicación silencio se refiere a una pausa, mientras que el tiempo se convierte en un elemento constitutivo esencial de todo relato, sea este literario, escénico o fílmico. En el texto de Duras, la indicación silencio imprime la marca única de la autora en la medida que parece indicar, a la vez, la cesación de toda voz y la indicación que precede la música en el filme, en este caso, el tema de Diabelli, que viene a llenar este silencio.

A fin de dar cuenta de la relación estrecha de diferentes formas mediáticas, el concepto de entrescritura (entrécriture), elaborado por Julie Beaulieu, nos permite reflexionar sobre la naturaleza intermedial del "texto teatro filme". Para Beaulieu, la entrescritura comprende, por una parte, el cruce de prácticas textuales, teatrales y fílmicas que constituyen la obra durasiana, es decir: "una escritura que se sitúa en la encrucijada de prácticas, géneros y discursos" (Beaulieu, 2014, p. 66). Por otra parte, la entrescritura da cuenta igualmente, de la práctica durasiana de reescritura, pues en el interior de la obra los relatos se comunican entre sí y retoman frecuentemente temas y personajes. A manera de ejemplo, la música presente en Le Camion, la cual consiste en tres variaciones de Beethoven sobre un tema de Anton Diabelli, hacen eco de otras creaciones de Duras, pues este tema reaparece igualmente en el texto y el filme India Song y es mencionado en la novela Moderato Cantabile (1958). En Le Camion, el tema de Diabelli se escucha tanto en las escenas de exteriores como en las interiores. Su utilización ejemplifica la repetición y la variación como elementos centrales de la poética durasiana.

Las tres formas de escrituras y prácticas que constituyen la relación "texto teatro filme" en el seno de la película Le Camion muestran una predominancia del texto o más precisamente, 
de la voz que lleva el texto. En el filme es la palabra la que da a ver, la que muestra más de lo que lo hace la imagen misma. La escucha del texto leído exige que el espectador recurra a su imaginación, con ayuda de la cual podrá "percibir" la historia que nunca es puesta en imágenes. Quien ve y escucha se convierte en un lector-espectador, ya que está ubicado frente a un diálogo, en principio teatral, que es filmado, pero en el que el texto subsiste, es decir, se constituye en fundador del sentido. El acto de lectura que se desarrolla en la pantalla parece evocar la figura del narrador oral, aproximando la oralidad y la literatura, pero de una "oralidad mediatizada", para retomar el término empleado por Beaulieu (2007, p. 185).

\section{La escritura en movimiento}

En el filme Le Camion, la pieza de la casa de Duras donde la puesta en escena de la lectura se desarrolla es denominada, según las indicaciones texto, la "cámara oscura", y especifica que, salvo la voz en off, toda la obra se ha de desarrollar en ese lugar (Duras, 1977, p. 11). La cámara oscura es, entonces, el lugar de lectura del texto, pero también nos lleva, de manera ambivalente, al mundo de la imagen, puesto que la cámara oscura es un antiguo dispositivo de proyección de la luz que precede la invención de la fotografía y la llegada del cine. La cámara oscura se muestra como un lugar de lectura y de visibilidad de la imagen. En efecto, la lectura del texto lleva a la imagen, al menos a la que produce el imaginario del lector-espectador para consumar la historia.

Esta cámara oscura es un lugar de mediación por excelencia puesto que evoca varios medios, principalmente el teatro, el cine, la fotografía, la literatura y la música, esta última a través del tema de Diabelli. Resulta entonces, como un ejemplo del diálogo establecido entre esos medios y el cruce de "géneros y discursos" a la luz del concepto de entrescritura concebido por Beaulieu.

Sin embargo, la cámara oscura es, antes que nada, el lugar donde el texto se hacela imagen. Privandoalpúblicodeverelfilme, atravéslalecturadelguion, Durasinvitaalespectadoraimaginarla historia contada. Esto supone una afirmación implícita de la supremacía del texto sobre la imagen.

\section{El libro y la imagen}

En la obra durasiana, el pasaje del texto al filme suscita un conflicto, el de la pérdida de la autonomía del escritor: para Duras, el paso de la palabra a la imagen sería "pasar a un acto de destrucción del creador del libro" (citado en Royer, 1985, p. 22), en la medida en que el filme destruye el libro. El texto apela a la imaginación del lector, mientras que el lenguaje fílmico priva de la misma al espectador. El mundo profílmico (el decorado, la iluminación), como todo lenguaje cinematográfico, impone o al menos, conduce el espectador a 
una "lectura" del libro a la pantalla. Algunos estudiosos de Duras han señalado esta problemática. Royer subraya que la palabra y la imagen "se dirigen a la imaginación de maneras diferentes" (1985, p. 24). La imagen empobrece lo imaginario en el lector mientras que el libro no lo agota y, por el contrario, le abre tantas posibilidades como lecturas haya. Es la razón por la que en el texto Le Camion, Duras desconfía de la "clausura que se llama filme" (Duras, 1977, p. 75). El imaginario suscitado por el texto es oprimido por la imagen: el cine no podría reemplazar el libro, lo cual afirma la supremacía del texto sobre la imagen.

Al respecto el empleo del condicional, tanto en el texto publicado, como en los diálogos pronunciados por Duras y Depardieu, es anunciado en la apertura del libro, que tiene por epífrafe un fragmento de la gramática Le bon usage, de Maurice Grevisse. El condicional hace referencia directa a la imaginación: "es empleado también para indicar una simple imaginación que transporta de alguna manera los acontecimientos en el campo de la ficción (en particular, un condicional pre-lúdico empleado por los niños en sus proposiciones de juego)" (Duras, 1977, p. 10). Lo lúdico, la imaginación y la ficción conducen al acto de contar una historia, para lo cual se pide la participación imaginaria del lector. Esta potencia de la palabra es propia del cine durasiano, que se sostiene sobre la voz off en la mayor parte de sus filmes. Ella explica: "En general, encuentro que todas las imágenes, o casi todas, estorban al texto. Ellas impiden que el texto sea escuchado. Y lo que quiero es esa cosa que deja pasar el texto. Todo mi problema es ese. Es por lo que India Song ${ }^{3}$ la hice en voz en off' (Duras, 2014a, p. 14).

La imagen sería un obstáculo para que el texto sea escuchado. Es así como, para Duras, lo imaginario se confronta a la imagen (lo cinematográfico). En efecto, como lo señala un crítico de Cahiers du cinéma, Duras habrá puesto todo su cine en condicional: "No hay fundamentalmente cine más infantil, ni cine más prendado de juego que el suyo: su juego comienza con la separación de la imagen y el sonido" (Azoury, 2014). La fuerza del cine de Duras reposa en la potencia de la palabra, y Le Camion es un ejemplo de ello. Además, el portador "indefinido de imágenes" es el texto, del que el cine no puede brindar ni superar su "potencial ilimitado ... su proliferación ilimitada de imágenes" (Duras, 1977, p. 75).

Es esta escritura que lleva las imágenes lo que el camión representa: "Sí. Mira su recorrido. Como un trazo. Una escritura: indescifrable. Y clara." (Duras, 1977, p. 34). El camión es la metáfora de la escritura, ya que el transporta todo "lo escrito del mundo", y eso que la autora designa como "imagen", o "la escritura portadora de todo, portadora de imagen como si se

\footnotetext{
${ }^{3}$ Según Julie Beaulieu, el subtítulo original del texto India Song. Texto teatro filme, "evoca diferentes sistemas semióticos que pertenecen tanto al teatro como al cine" (Beaulieu, 2014, p. 74).
} 
hubiese corrompido la escritura" (Duras, 1977, p. 92). Es así como Duras afirma el lugar de la escritora:

Se escribe, todo el tiempo, se tiene una suerte de alojamiento en sí, de sombra, donde todo va, donde la integralidad de lo vivido se amasa, se amontona. ... En el filme, el camión transporta esa masa. Todo lo escrito del mundo. Como si eso pudiera medirse, pesarse: treinta y dos toneladas de escritos, eso me gusta. Es eso que yo llamo: la imagen (Duras, 1977, p. 105).

El cine sería entonces "una puesta en imagen, una ilustración de la historia, donde la palabra no es más la palabra, donde ella no tiene más su poder, su potencia, donde la imagen es forzada e intenta sostener la ausencia de la palabra." (p. 92). Son, en efecto, la escritura y la palabra las que tienen el potencial de despertar la imaginación del espectador, ya que "el cine no consigue responder más a la sed creciente de conocimiento del espectador" (p. 76). Sin embargo, el camión lleva también trazos de cine. Su desplazamiento por la carretera evoca el movimiento de la cámara, el travelling. Mientras que la cabina corresponde al cuadro por el cual se ve el paisaje, el plano y el encuadre, y es en esa cabina que permanece la dama del camión. Es decir, borrar o ignorar el cine resulta imposible, ya que los lenguajes están en movimiento y se cruzan. El camión representa así la ambigüedad entre lo escrito y la imagen. Él posee además el potencial de fabricar imágenes, comprendida la imagen cinematográfica. Esto demuestra como en Duras el lector será siempre el lector-espectador.

\section{La dama del camión, la cabina, la cámara oscura}

La dama que ocupa la cabina del camión, a un costado del conductor, es un personaje que parece venir de ninguna parte. Ella habla de política, de injusticia social, de viajes, de una villa que ella habría habitado en su infancia, del amor y de la escritura. No obstante, Duras parece darle una función: "es por ella que yo veo. Por ella que tomo el exterior y que lo engullo" (Duras, 1977, p. 79). La dama del camión representa algo. Aunque la dama del camión, como una cámara, dirija su mirada hacia el exterior, ella es la portadora del texto puesto en el que la cabina es un lugar de escritura y de creación de la imagen. La misma Duras explica a los lectores, a quienes interpela:

El ambiente cerrado de la cabina, ese es el primer encierro del filme, es ahí donde se hace lo escrito. El segundo encierro es el de la cámara oscura donde estoy con Depardieu, es allí en ese escrito que ustedes están. El resto del filme está vacío, vacío de personajes, no hay más que ese objeto, el camión que transporta, yo diría, el texto" (p. 94).

Es a través del personaje de la dama del camión que la autora ve. Duras parece querer sacar sus personajes de la oscuridad, inspirarse en personas reales que se encuentran en los márgenes de la sociedad o están impedidas de ser vistas, como los mendigos, los locos, los sin 
papeles $^{4}$. La dama del camión tendría entonces una función de "portavoz", como señala la crítica de cine Marie-Anne Guérin:

Marguerite Duras hace de esta dama la autora de su historia. El cine es indiferente o cruel, con quien no existe. Es por eso que hay actores y autores. Sin embargo, la potencia intrínseca del cine va más allá de autores y actores. El filme de Duras responde al llamado de una mujer que pide no un cuerpo de actriz, sino un cineasta, que le brinde un espacio para describir y mostrar lo que ella ve. La dama de Le Camion no tiene nombre, ella se confunde con la autora, ella espera el filme, ella lo lleva, su mirada se apodera de lo real con una capacidad lingüística formidable. Ella está, como dice Duras, "volteada hacia el exterior"(Guérin, 2007).

Como el cine de Duras, que rechaza toda clasificación y etiqueta, la dama del camión es también una déclassée ${ }^{5}$. Ella encarna entonces a la cineasta y sus inquietudes a nivel técnico, pero también aquellas que son de naturaleza política y cultural. Duras se sirve del filme inacabado para reflexionar sobre el cine y la literatura. La operación es entonces autorreflexiva y autorreferencial. La cabina del camión y la cámara oscura representan la distancia entre el cine y la escritura, la imagen y lo imaginario:

Yo los veo encerrados en la cabina, como amenazados por la luz exterior (Tiempo). Tengo la impresión que ustedes y yo también, estamos como amenazados por esa misma luz de la cual tenemos miedo: el temor que de una vez se meta en la cabina del camión, en la cámara oscura, una oleada de luz, ¿ven? (Duras, 1977, p. 42).

El conflicto no es la imagen (cinematográfica), en general, ni la imaginación del espectador, sino el cine comercial, que Duras considera una trampa que amenaza la inteligencia del espectador, como lo constatamos en esas reflexiones, explicadas en el paratexto "Segundo proyecto", incluido en la versión libresca de Le Camion:

"El cine está espantado, él se bate, lucha, se ahoga para encontrar otras vías diferentes de la palabra para responder a la inteligencia creciente de su espectador, para aprehenderla y meterla en sus salas de proyección, para que siga consumiendo su producto" (Duras, 1977, p. 75).

\footnotetext{
${ }^{4}$ Podemos citar como ejemplo Le ravissement de Lol VStein (1964), cuyo personaje se inspira de una mendiga de un asilo visitado por Duras. En ciertas obras, como Le Square (1957), la autora hace también referencia a diferentes nacionalidades que han abandonado su país por razones políticas para refugiarse en Francia.

${ }^{5}$ Este es un juego de palabras de Duras: déclassée significa "desclasificada" o "desordenada", pero principalmente , "sin clase" (social), "empobrecida".
} 
Según Cléder, el desprecio de Duras por el cine comercial puede explicarse "en el plano político, puesto que acusa al espectáculo político, al espectáculo capitalista, de alienar el espectador y de prohibirle el acceso a lo imaginario" (Cléder, 2013, p. 81). Según Duras, el cine comercial privilegia la imagen: "Hace cuarenta años que el cine tiene vergüenza de la palabra" (p. 94). Es un cine que rehúsa explicarse, que rechaza el lenguaje. En su entrevista con Michelle Porte, también incluida en el libro Le Camion, Duras explica su admiración por el cine de JeanLuc Godard, quien habría inventado un cine que "no toma a su espectador por un niño" (p. 96). En efecto, Godard ha brindado la misma importancia a la palabra como a la imagen en sus filmes. Además, en tanto que intelectual, este cineasta comparte la preocupación de Duras de cara al cine comercial. En su obra fílmica L'Histoire(s) du cinéma, Godard interroga el lugar del cine francés y europeo de cara a la potencia del cine estadounidense, percibido como una industria de entretenimiento en la que el espectador es considerado como un simple consumidor.

Habiendo rechazado toda etiqueta y clasificación, el cine de Duras es, antes que nada, fiel a sus propias convicciones. Por ello, la autora se reserva un espacio de libertad para explorar sus preocupaciones alrededor de la representación:

Yo creo que lo que he querido hacer en Le Camion, empleando ese tiempo, el condicional perfecto, ese tiempo lúdico, es hurtar al espectador una cierta representación. Reemplazando esta representación por un texto, yo iba a decir que, impersonal, despoblé el filme de algo. Y yo lo hago también con India Song, con las voces de los actores. Yo les retiro la voz (Duras \& Noguez, 2001, p. 155).

A través de esa toma de posición, expresada en entrevistas y en la presentación de sus obras, Duras afirma su desconfianza respecto a la sociedad del espectáculo, que tiene por función cegar al espectador. El filme es aquí considerado como un producto del cine comercial, sostenido por la industria cultural, y atrae al espectador por la potencia de la imagen. Eso justifica incluso la ironía subyacente en el filme Le Camion, ya que no llega a convertirse en filme, pues los medios no alcanzan.

En Le livre dit (2014b), Duras destaca la cuestión del prejuicio de la representación. Ella se refiere al cine comercial y lo contrasta con sus filmes India Song, Le Camion y el posterior Agatha et les lectures illimitées:

Es decir que es necesario terminar con el prejuicio de la representación. Si se muestra una escena se puede también mostrar como ella ha sido filmada; es así, tú ves. Se puede también mostrar cómo la cámara filma la escena: es tanto cine como la escena filmada por la cámara. A mí, eso es lo que me interesa. Tú filmas una escena de amor, tu tienes la escena de amor ... Tú cortas la escena y es eso lo que muestras al público. Y a mí, me gustaría mostrar cómo ha sido rodada. Eso que he intentado en Le Camion, es lo que intento hacer en Agatha. Pero no es sistemático; es 
un poco menos del tercio del filme que es mostrado así, que es evidente, pero no en todo el filme. Eso me excita mucho. Dar al público como se hace el cine, la presencia del cine (p. 145).

Al contrario de lo que pasa en el cine comercial o en el cine comprometido, Duras parece tener la libertad de realizar un cine donde ella pueda explorar sus propias reflexiones alrededor de la representación. Un cine inclasificable, en el que la cabina del camión y la cámara oscura revelarían a la vez la cara de la cineasta y de la escritora. No obstante, es en el cruce de prácticas intermediales y en el interior de las cuales, ninguna práctica se impone, ni film, ni texto ni teatro, sino la voz.

\section{Conclusión}

La representación cinematográfica, Duras parece, por una parte, confirmar su lugar de escritora, incluso si este implica una paradoja: la puesta en escena del texto leído y filmado, inscribe la oralidad en visualidad y temporalidad del cine. Además, la puesta en escena evoca la figura del narrador oral, y hay que decir que el arte de contar precede históricamente todas las expresiones ficcionales. El lugar designado como la cámara oscura no se debe al azar, puesto que este se convierte en el espacio donde todos los medios evocados en el filme y el texto interactúan y se cruzan, un lugar de diálogos intermediales por excelencia. La cámara oscura y la cabina del camión representan, a la vez, el escrito y la imagen. Por otra parte, el camión constituye una metáfora del escrito que porta la imagen.

En lo que concierne, la representación, sobre el vínculo establecido entre el texto y el filme, algunos críticos sostienen que disociar el cine de Duras de su literatura haría la obra incomprensible. Le Camion testimonia el carácter experimental del cine durasiano. En ese sentido, establecer la relación entre el texto y el filme resulta imposible, porque el texto habla del propio filme inacabado. Para Duras, no obstante, pasar del libro a la pantalla implica los desafíos de representación impuestos por las convenciones del medio. Duras parece querer destruir la representación cinematográfica a fin de privar al espectador de la imagen, para que él pueda imaginar la historia.

$\mathrm{Al}$ respecto, Duras impone, por una lado, la supremacía del texto sobre la imagen y por otro, parece querer despertar al público de la ilusión del cine comercial. Asimismo, al rechazar la actuación a través de la lectura del diálogo, Duras parece optar por ayudar a crear un efecto de distanciación. Así, es por el cruce de prácticas mediáticas que se puede comprender este filme que evoca lo escrito, la imagen y la voz a través del cine, el teatro y el texto. 


\section{Referencias}

Azoury, P. (2014) 30.000 ans devant la mer. En Filmer, dit-elle. Le cinéma de Marguerite Duras. Paris: Capricci.

Barat, F. \& Barat,P. (Productores) \& Duras, M. (Director) (1977) Le camion [Película]. Francia:Auditel, Cinéma 9.

Beaulieu, J. (2014). “Ce qui reste du théâtre dans le film: le "cas” Marguerite Duras”. Études littéraires, 45(3) : 65-79.

Beaulieu, J. (2007) 'La chambre noire' dans Le Camion de Marguerite Duras. En Myrien El Maïzi y Brian Stimpson (Eds.), Marguerite Duras 2: "Écriture, écritures" (pp. 179-191). Paris: Lettres Modernes Minard.

Borgomano, M. (1985). L'écriture filmique de Marguerite Duras. Paris: Albatros.

Cléder, J. (2013). Entre littérature et cinéma : inventer une langue étrangère?. En L.T., Najet (Dir.). Marguerite Duras: Altérité et étrangeté ou la douleur de l'écriture et de la lecture (pp.79-88). Rennes: Presses Universitaires de Rennes.

Duras, M. \& Noguez, D. (1984). La couler des mots. Entretiens avec Dominique Noguez. Paris: Benoit Jacob.

Duras, M. (2014a). Dialogues, avec Jean-Luc Godard. Paris: Post éditions.

Duras, M. (2014b). Le livre dit. Entretiens de Duras filme. Paris: Gallimard.

Duras, M . (1977). Le camion suivi d'Entretien avec Michelle Porte. Paris: Minuit.

Godard, J. L. (1998). Histoire(s) du cinéma. Paris: Gallimard y Gaumont.

Guérin, M.A. (2007). Duras-Depardieu dans Le Camion: la rencontre entre une porte-parole et un corps porteur du récit. En J. Aumon. (Dir.). La Rencontre (pp.261-276). Rennes: Presses universitaires de Rennes. P.

Royer, M. (1985). L'Écran de la passion. Une étude du cinéma de Marguerite Duras. Queensland: Boombana. 